\title{
DEVELOPMENT OF A NEW EXPERIMENTAL WEB TENSION CONTROL SYSTEM
}

\author{
GIANNOCCARO, N.I. \& SAKAMOTO, T.
}

Abstract: In this paper a new experimental system and controller for web transport system is developed and tested and the related mathematical model investigating the dynamics of the web is validated. The experimental set-up consists of four sections each of which is driven by a servomotor; the speed and the tension control is realised by using the feedback of encoder and tension sensors and driving simultaneously the four servomotors through a real time $C$ programmed D/A board.

Several considerations about the set-up of this new experimental system and comments about the controller performances are shown in this paper. Moreover some considerations about the lateral moving web are allowed by using a couple of tension sensors for each tension controlled section.

Key words: Winding systems, Decentralised control, Web tension control, Experimental systems design
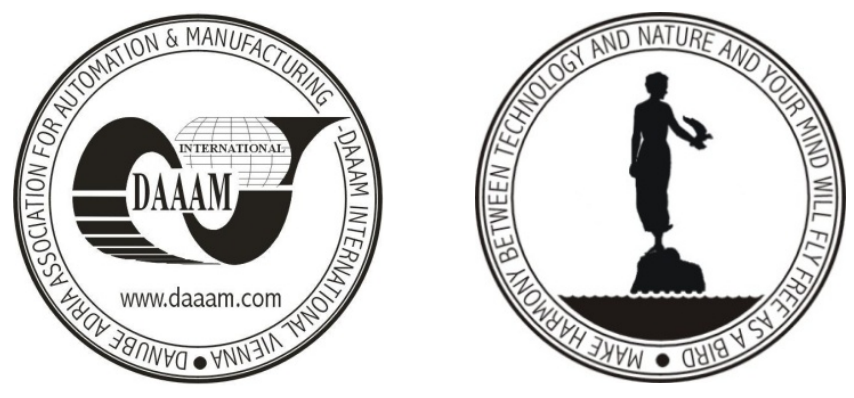

Authors' data: Dr. Giannoccaro, N[icola] I[van]; Sakamoto, T[etsuzo], Dipartimento di Ingegneria dell'Innovazione, Università del Salento, Via per Monteroni, 73100, Lecce, IT, ivan.giannoccaro@unile.it, sakamoto@cntl.kyutech.ac.jp

This Publication has to be referred as: Giannoccaro, N[icola] I[van] \& Sakamoto, T[etsuzo] (2008). Development of a New Experimental Web Tension Control System, Chapter 26 in DAAAM International Scientific Book 2008, pp. 301-316, B. Katalinic (Ed.), Published by DAAAM International, ISBN 978-3-901509-66-7, ISSN 1726-9687, Vienna, Austria

DOI: $10.2507 /$ daaam.scibook.2008.26 